\title{
Does engagement in Forest School influence perceptions of risk, held by children, their parents and their school staff?
}

Alice Savery, Tim Cain, Jo Garner, Tracy Jones, Emily Kynaston, Kirsten Mould, Laura Nicholson, Sophie Proctor, Rosanne Pugh, Emma Rickard \& Deborah Wilson

\begin{abstract}
In a climate where, it is claimed, children now spend very little time out of doors because adults fear for their safety and impose a 'zero risk childhood' on them, Forest School aims to offer learners the opportunity to take 'supported risks'. This study investigated perceptions of risk associated with the outdoors, held by children, their parents and practitioners, and whether accessing Forest School impacts on these perceptions of risk. Practitioners were generally either strongly risk-averse or strongly permissive; Forest School influenced them to be less risk-averse in some respects. Parents held ambiguous perceptions, wanting to keep their children very safe but also to help them develop strong and confident attitudes to risk. Implications for research and practice are discussed.
\end{abstract}

\section{Introduction}

Risk may be defined as a systematic way of dealing with hazards and insecurities induced and introduced by modernization (Beck 1992, 21).

Risk is said to be omnipresent among contemporary Western people, in what some have called the 'risk society' (Beck 1992; Giddens 1999). Giddens (1999) argues that the concept of risk was unknown to pre-industrial societies, who attributed disasters to luck, fate, or the will of the gods. Risk, and the calculation of risk, came into being in the seventeenth century, with the emergence of companies that would insure sea voyages against disaster and, for a time, it seemed that risk could be contained: measured, insured against and thus to some extent, controlled. Beck (1992) argues that the proliferation of manufactured hazards, especially nuclear power, environmental despoliation and genetic technology, has rendered risk unmanageable and hence, induced high levels of anxiety into contemporary, lived experience:

The driving force in the class society can be summarized in the phrase: I am hungry! The movement set in motion by the risk society, on the other hand, is expressed in the statement: I am afraid! (Beck 1992, 49)

According to Giddens (1999) the risk society '... is a society increasingly preoccupied with the future' and it has been caused, at least in part, by two 'fundamental transformations', both of 
which are connected to the increasing influence of science and technology 'the end of nature' and 'the end of tradition' (Giddens 1999, 3). As Giddens (1999) explains,

The end of nature does not mean a world in which the natural environment disappears. It means that there are now few if any aspects of the physical world untouched by human intervention ... For hundreds of years, people worried about what nature could do to us - earthquakes, floods, plagues, bad harvests and so on. At a certain point, somewhere over the past fifty years or so, we stopped worrying so much about what nature could do to us, and we started worrying more about what we have done to nature. The transition makes one major point of entry in risk society. It is a society which lives 'after nature'.

In this 'risk society' which lives 'after nature', it is claimed that children now spend very little time out of doors (Moss 2012) because adults fear for their safety and impose a 'zero risk childhood' on them (Gill 2007). Instead, they spend their time indoors, 'reared in captivity' (Gill 2013) in 'electronic bedsits' (Palmer 2011). Fears and anxieties for children are exacerbated by media presentation of particular tragic cases of child abduction and murder (Gill 2007). Gill (2007) expresses concern that childhood experience is becoming undermined by adult risk aversion because,

... children in the past have been assumed to have capabilities that we now rarely think they have... so fixated are we on giving our children a long and happy childhood that we down play their abilities and their resilience' (Gill 2007: 11)

According to a report for the National Trust, children spend, on average, over seventeen hours every week watching television, and 11-15 year-olds spend about 7.5 hours a day watching screens of one sort or another (Moss 2012: 4; see also National Trust, n.d.). In addition, 'Fewer than one in ten children regularly play in wild places' and 'Children are unable to recognise common wild creatures' (Moss 2012: 5-6).

This risk-averse, indoor movement seems to be a fairly recent, cultural development rather than a natural human disposition. Although historically, most education would be expected to take place out of doors, the institutionalisation of education has meant that, 'the classroom or indoor setting is now so firmly regarded as the usual place for learning that significant government efforts and research evidence about how the outdoors may enable learning .... are needed to redress the balance' (Waite 2010: 112). Whereas previous generations of children in Britain were used to roaming freely outdoors, participating in 'risky' activities such as tree climbing, using a penknife or simply exploring without adult supervision, this occurs less frequently, today (Gill 2013). Looking abroad, the risk-averse mentality doesn't appear to be preventing 
children assessing and managing their own risks. For example, a recent documentary set in Brazil showed children of all ages - some not even walking, working with their mothers using bladed tools, harvesting food in the field. Only the British adult visitor sustained an injury from the use of the tool (BBC, 2014). Palmer $(2009,162)$ concurs:

... within a generation, the traditional freedom to roam, explore and learn from firsthand experience of their world has for many boys all but disappeared. Instead, they're closeted away in their bedrooms, exploring the virtual world of screen-based entertainment.

Although commentators tend to focus on parents as a main source of risk aversion, Knight $(2011,4)$ acknowledges that teachers and other educational practitioners often find the idea of facilitating risk taking activities with children challenging, sometimes 'anticipating opposition from managers, colleagues and parents'. Practitioners can be, '... very nervous of the contemporary push towards more outdoor play, and the encouragement from advisors and others to provide more opportunities for children to take risks and have adventures (Knight 2011, 1). A House of Commons report found health and safety concerns and resultant fear of litigation as major barriers to learning outside the classroom (House of Commons 2010) and a large-scale survey in England confirmed that Early Years practitioners saw 'a risk-averse culture' as a barrier to outdoor learning (Waite 2009: 8). Further barriers included reduced funding for outdoors learning and an overarching approach to education that emphasises learning that can most easily be tested:

... current emphases on measurement remain a barrier to the uptake of outdoor opportunities for learning for many practitioners; especially as this is compounded by reduced funding for what is currently seen as peripheral activity (Waite 2010: 123).

Furthermore, even when parents and practitioners see the benefits of risk-taking play, a combination of regulatory factors and a safety-first attitude to playgrounds means that, ... the types of playgrounds typically available for young children appear to offer little challenge or opportunity for risky play. Tension exists between what parents and teachers believe are appropriate outdoor physical play experiences for young children and what is actually available in [Early Childhood] settings and playgrounds. (Little et al. 2011: 129)

Nevertheless, there is a clear positive case for risk in childhood. Articulating this case, Gill (2007) offers four main types of argument: 
1. Encounters with certain types of risk are said to help children learn how to manage those risks

2. Children have an appetite for risk taking... if not fed ... will lead them to seek out situations in which they maybe exposed to greater risks.

3. Children gain other benefits as a side-effect of being given the chance to undertake activities with a degree of risk (that the risks are greatly outweighed by the health and developmental benefits)

4. Longer-term benefits of risk encounters - that children build their character and personality through facing up to adverse circumstances where they know there is the possibility of injury or loss. (p. 16)

With regard to health and developmental benefits, Louv (2005) has identified a growing body of research that links our 'mental, physical and spiritual health directly to our association with nature -in positive ways' going on to say that 'we can now assume that just as children need good nutrition and adequate sleep, they may very well need contact with nature' (p. 3).

\section{Forest School}

Forest School enables learners to access the outdoors, commonly as part of their school week, incorporating regular exploration of an outdoor space, either in their school grounds or in a local patch of woodland. Forest School is an approach to education that is derived from observations of Scandinavian early years education. It embraces the outdoors as a learning environment, with regular outdoor sessions, planned around the interests of the children. As Knight (2009) states, 'it resonates with those of us who spent our childhoods either in woods and field or around an area of streets, messing about with mud and sticks and learning without noticing' (p. 2). The Forest School approach is defined by the Forest School Association (FSA) (2012) as,

... an inspirational process, that offers ALL learners regular opportunities to achieve and develop confidence and self-esteem through hands-on learning experiences in a woodland or natural environment with trees (n.p.)

There are six principles of Forest School that make it distinct from other forms of outdoor learning. One of these principles is that the sessions are led by a qualified Forest School Leader, someone - usually (but not exclusively) a member of staff from their setting or school who has completed the relevant qualification. In many cases this is the child's class teacher, who is responsible for delivering the entire curriculum to the class. Another principle is, 'Forest School offers learners the opportunity to take supported risks appropriate to the environment and to 
themselves' (FSA 2012). In Forest School, 'children learn about risk and to take risks that challenge them but do not lead to harm' (O’Brien 2009, p. 52). Waters and Begley (2007) studied risk-taking behaviours in four year olds at their Forest School setting and at their outdoor play space at school and looked at the contrasts in the play in the two outdoor environments. They found that Forest School was better able to support the risk-taking behaviours than the school outdoor play-space. They found that risk is often associated a negative way, and as Knight (2011) found, staff perception of risk can limit children's experience and that practitioners at school could have 'considerable anxiety about children taking risks'. The study showed that there was a permissive approach to risk at Forest School (Waters and Begley 2007: 356) and that this permissive ethos relating physical challenge was clearly and consistently applied at Forest School (p. 372). This was found to contrast with a regulatory approach employed inconsistently in the outdoor space at school.

Maynard (2007) also studied risk taking at Forest School, focussing on the differing perspectives of the school staff that accompanied the children and the Forest School leaders that delivered the sessions. From diary accounts of both parties there was a clear difference in approach, the teachers saying they had to 'intervene' for the children's safety whereas the Forest School leaders interpreted the same events as the teachers 'interfering' with the children's own learning and self-discovery. Knight (2011) describes risk taking at Forest School; When I take three- year-olds into the woods for Forest School sessions, we spend a lot of time talking, before, during and after the sessions. For some of them, a wood is in itself scary, being dark and unknown, and I want them to benefit emotionally, intellectually and physically. A child can't do that if s/he is scared or if s/he is unaware of danger. Bravery is not about rushing in blindly - it is about knowing the risks and doing the best you can. So we talk about nettles and brambles and holes in the ground, amongst other things that are part of that environment they will need to learn to manage. We do not remove them (p. 5)

Rather than removing the dangers such as harmful flora but educating the children how to identify them and why they pose a danger helps children to understand and manage the hazards in that environment. This understanding is a child making an informal assessment of risk and therefore judging for themselves if they can safely negotiate that environment. Gill (2010) discusses 'an approach to risk management called risk-benefit assessment that aims to assess and manage both risks and benefits together' (p. 15). Forest School practice reflects this, not taking risk for risk's sake, but for acknowledging the benefit to the participant of the risk taking 
activity and finding the developmental benefit outweighing the likelihood of a negative experience:

By their very nature, Forest School programmes require a thoughtful approach to balancing risks and benefits. The activities on offer may include building dens, using knives and tools, and fire-based activities, with children being given significant choice and control over what they do (Gill, 2010:18).

In brief, it is claimed that Forest School promotes a healthy approach to risk, countering a strongly risk-averse tendency in society by offering children the opportunities to take some risks within an environment that will protect them from the worst consequences of risk.

\section{Methods}

To investigate whether this effect is actually perceived by children, their parents and practitioners (their school or pre-school setting staff) this research sets out to discover,

- The perceptions of risk associated with the outdoors, held by children, their parents and practitioners

- Whether accessing Forest School impacts on these perceptions of risk

This study focused on children aged between 3 and 7 years old and their parents and practitioners. We consulted those that had accessed Forest School and those that had no involvement in Forest School, in order to include a comparative element to the research.

The research has been undertaken in an English rural county. The research team consists of a Lead Researcher who coordinates the Forest School approach in the area, and a team of eight Research Practitioners who are staff from schools and settings in the county. All the researchers are experienced Forest School Leaders and regularly deliver Forest School sessions with children aged between 2-16 years-olds. This research project has been supported and mentored by an English University. A range of geographical areas within the county were used and both rural and urban settings of varying sizes and of differing economic backgrounds, including one specialist school for children with learning difficulties.

A mixed methods approach was used, involving both qualitative data and quantitative data: individual, structured interviews were used to ascertain perceptions of risk, and questionnaires, to gauge the extent to which the perceptions, revealed in the interviews, are widely held. Purposive sampling was chosen so that, in each of the three groups (children, parents and practitioners) roughly $50 \%$ had accessed Forest School and the other 50\% had no experience of Forest School, enabling comparisons to be made. In total, the Research Practitioners 
interviewed 23 parents, 22 practitioners and 37 children; completed questionnaires were received from 191 practitioners and 122 parents.

Interviews were conducted by Research Practitioners who are known to the children and parents in their school or setting, at a time convenient to them within a normal working day. This was done so as to make the interviews as natural as possible, especially for the children. Before the interviews began, the interviewees were informed of the content and the purpose of the interview and had the opportunity to decline. Participants signed a participant information sheet and consent form and parents were also given the right to decline for their child to be interviewed.

Interviews were recorded on audio recording equipment, to enable a natural flow of conversation that can be affected by writing down interviewee comments. Interviews were transcribed anonymously although we acknowledge that in the transcribing process, some of the detail and context has been lost, as the social setting of the interview has been removed. Additional data were gathered from comments boxes which were set up in some of the participating settings, with sheets for parents to record anonymously, 'any comments or concerns about Forest School'. Circle time at the end of the Forest School session was also recorded in four settings, with children discussing their perceptions of risk and safety at Forest School.

The research team met termly to discuss the project and evaluate each stage. Minutes were kept from these meetings and the discussion about the process and on-going findings helped shape the project as it progressed. Quantitative data were analysed with SPSS software; p values were adjusted for one-tailed tests. (p must be below .003 to be significant as a Bonferroni correction was applied.) Cohen's d indicates the effect size: 0.2 is a small effect; $d=0.5$ is a medium effect; $\mathrm{d}=0.8$ is a large effect. (See Table 1.)

In order to address the complexities of social interaction within the delivery of Forest School and the perceptions of risk, the data were coded and themes and categories were identified. These themes were analyzed quantitatively by count the number of occurrences of the themes (Taylor Powell 1996). Data were analyzed individually and as a whole group to define collective perception of risk, again by looking for patterns in the three themes (Cohen et al. 2011) We are aware of a range of factors that might have affected responses from participants. Although the interviews appeared full and honest, there might have been an element of interviewees saying what they thought we expected to hear. But with the addition of anonymous questionnaire data, we feel a reasonably reliable picture was revealed. This 
triangulation enabled us to cross-check the accuracy of findings and to clarify meanings, helping to ensure an authentic picture by representing multiple perspectives (Taber 2007:82).

\section{Quantitative Findings}

Parents and practitioners were asked to register on a 5-point Likert Scale (strongly agree strongly disagree) their agreement to a set of statements, constructed with regard to the research literature and our own experiences of Forest School:

1. It is important that an adult can see every child at all times

2. I don't mind my children getting muddy

3. It is more difficult for staff to manage behaviour out of doors than indoors

4. Children should be allowed to climb trees if they feel safe doing so

5. I would be concerned if my children were out of sight of an adult

6. I would be concerned if my children were using knives

7. If my child has an accident, their parents might sue the school

8. Children who are allowed to take lots of risks at a young age will take risks as teenagers, which might get them in trouble with the police

9. When they are walking, children should hold hands

10. Glass and other unexpected items aren't a problem if children are taught how to deal with them

11. If children use tools, it is important that they are not sharp

12. Children should stay on task to meet the desired learning outcome

13. Children can be taught to use knives from an early age

14. I don't mind my children taking risks as long as I know a full risk assessment has been written

15. Children learn best when indoors in a controlled environment

Children were asked similar questions but in a more child-friendly language, in face-to-face interviews. Although we intended to enter their results in a Likert scale, in practice this was not possible because we found that many children did not really understand the 5-point scale; this rendered their results meaningless.

Data analysis compared those practitioners who had experienced Forest School with those who had not. For all questions, the descriptive statistics showed that responses moved in the direction of being less risk-averse. The following table shows the responses of practitioners. Significant differences were found for statements 1 ('It is important that an adult can see every child at all times'), 9 ('When they are walking, children should hold hands'), 11 ('If children use 
tools, it is important that they are not sharp') and 13 ('Children can be taught to use knives from an early age'), with moderate effect sizes for each question. Statement 3 ('It is more difficult for staff to manage behaviour out of doors than indoors') was close to significance (See Table 1). There were no significant differences detected in the parent data.

\section{INSERT TABLE 1}

\section{Qualitative Findings}

Perceived risks

Perceived risks, identified by practitioners, are largely environmental ones: mud, cold and water, together with specific worries about bottles and broken glass, flora such as Blackthorn and nettles, and insect bites or stings. Other risks are those associated with Forest School activities, including using knives, having fires and climbing trees. Parent interviews revealed other perceived risks children may be exposed to when playing outside. One mother said they thought that parents would be concerned if their child was out of sight of an adult 'especially these days, it's quite worrying' (Parent 20) referring specifically to fears about abduction. Another concern relating to being out of sight of adult was that the child may 'fall into a great big ditch and drown or disappear into anything dangerous' (Parent 14).

Children being out of sight of an adult was a concern that was voiced by parents in particular. Some responses to this question suggested that the Forest School approach allayed this fear through the methods used during sessions. Examples of this included playing ' $1,2,3$ Where are you?', the Forest School site boundary, the Forest School leaders whistle - a cuckoo call in one case, and visiting the site as a family, prior to sessions commencing.

With regard to Forest School activities, fire and tree climbing were most often elaborated upon in the interviews. Fire area routines were mentioned, where young children do not go near the fire itself, but walk around the outside and step over their seating logs (in most cases) to sit carefully. Children have said how they don't go near to a lit fire unless they are cooking something. They also mention moving seats and shielding eyes if the smoke is coming towards them. Reference to tree climbing were predominantly from the children - one child noting that you don't climb if it is slippery, and others saying that an adult needs to be able to see you if you are climbing a tree and to what height they can climb to. Parents also stated how their children have reiterated these safety rules at home.

\section{Responses to risk}

In general, the qualitative data could be categorised as either risk averse or permissive (Waters \& Begley 2007). Examples of risk-averse comments were, 
I know that when I'm out with him and friends I'm always the one that's like 'oh G be careful, G be careful!' (Parent 14).

I'd rather I can see; I always say 'stay in my sight, stay where I can see you' (Parent 21)

I personally always like them to be in sight of an adult (Practitioner 18)

Each of these quotations implies a desire, constantly to monitor the children in order to keep them safe. In contrast, a permissive stance to risk taking, encouraging the child to take risks for themselves, can be seen in the following examples from the data,

A happy child is a dirty child (Parent 20)

[of tree climbing] No! I encourage it (Parent 1)

In these instances, climbing trees and getting dirty are signs of a risk-taking attitude and perhaps, greater independence. Occasionally the approach taken was expressed as permission within limits. We termed this a 'measured' approach, which was often seen in the context of Forest School sessions. For example, one practitioner, discussing parents' attitudes to their children climbing trees, said,

I think they appreciate it's a learning experience, a little bit of risk there, and children learn how much they can do, you know, if they can climb onto that lower branch there' (Practitioner 21)

And a parent expressed a similarly measured view:

I feel fully confident in all the activities that are taking place - there is just the right level of risk, the opportunities we've had to go to Forest School, we've been talked through the element of risk and how the risk thing is quite important so I feel quite comfortable with it (Parent 21)

This is not a gung-ho or blasé approach but one where the adult is happy for the child to actively judge the risk for themselves within an environment where the risk is at 'the right level'. This may involve the adult establishing some awareness of danger and boundaries but ultimately the child has a choice and is able to carry out their own informal, on-the-spot assessment of the risk involved.

The data indicated that practitioners sat in one camp or the other; they either held a risk-averse stance or permissive one and their responses were consistent with this stance. Whether they were risk-averse or permissive, did not appear to correlate to whether they were trained to work in Forest School or not. Parents were different; the majority had both elements to their responses. There was an acknowledgement of the permissive approach as being what they often 
believed is right, in some cases what they themselves used to do, and what they would like to allow their children to do. However this was often accompanied by a suggestion that they worry about their children, and aren't comfortable to let them take risks:

I'm quite happy for my children to be climbing trees, again as long as there has been risk assessments in place beforehand and the children again are doing it in a safe, controlled way. And it's all part of children's experience, that is what they like to do' (Parent 12)

In this response, there are elements of both a permissive attitude ('I'm quite happy ... it's all part of children's experience') but also risk-aversion ('again as long as there has been risk assessments in place beforehand and the children again are doing it in a safe, controlled way'). This parent wants 'again ... risk assessments' and 'safe, controlled' behaviour. This suggests, not so much a measured approach (the children assessing their own risks) but a slightly schizophrenic one. This approach was also found when comparing the practitioner data with that of the parents. Practitioners were asked both in questionnaires and interviews if they thought that parents would be concerned if their child was out of sight of an adult. The practitioners were confident that parents would be relaxed about this, but the parent responses were more ambiguous. Many parents responded with, 'some parents might... but I wouldn't', making it hard to tell if they were actually concerned themselves but didn't want to acknowledge that this was how they felt, or if they actually knew parents who had these concerns.

This raised the question of how practitioners communicate with parents in regard to the Forest School approach. It is possible, that because Forest School is so widespread that this communication is assumed by the practitioner rather than explicitly conveyed. Where parents have been involved with Forest School sessions there appeared to be a difference in their confidence and understanding of the Forest School approach, and a greater chance of them replicating Forest School type experiences as part of family life (Jones, 2013).

\section{Forest School and risk}

Parents appreciate that Forest School provides opportunities for learning and enjoyment. They mentioned 'more freedom for children, more relaxed environment' (Parent 9) and 'freedom to run round... not be cooped up indoors all the time' (Parent 14). However, they appreciate that the 'freedom' is in a protected environment. In some instances, their confidence in Forest School seems to lie in the fact that Forest School is 'controlled': 
It was nice because I knew that it was, in the nicest possible way that they were penned in to a point ... that meant they could just be free in a safe controlled environment, if that makes sense. (Parent 14)

In some cases, parental confidence is connected with the Forest School staff, their training and adherence to procedures, including risk assessments:

I know that you would be in the woods beforehand and you would have done the risk assessments and looked at anything that may have changed over the week and so I was confident that all the safety aspects have been covered' (Parent 12)

understanding of children's abilities to negotiate such risks :

As long as children are aware of the dangers of the fire and that they're not to go in the fire square and they are supervised. She tells me [about the fire area rules]' (Parent 13) and the physical boundaries around Forest School:

We know of the boundaries within the Forest School area and that the children were made well aware of them and that the children were able to show us the boundary' (Parent 23)

Other parents focused less on the staff and procedures and more on the intrinsic value of teaching children to think about risk and to develop a thoughtful response to risk, to understand risk of real-life situations and how they are not protected from danger:

I think it's invaluable that children learn and understand risk of real life situations and it's important that children know they are not protected from danger because otherwise they won't understand danger and be able to protect themselves in environments and conditions where they might not be being looked after' (Parent 15)

and how negotiating risks is an inevitable part of growing up:

To climb small trees I think is part of them growing, especially boys, so they learn to take risks and understand the risks that they are taking and understand how to get down as well' (Parent 22)

It is interesting that Parent 22 singles out boys as risk-takers; further research might investigate whether parental attitudes to risk are different for boys and girls. There is also evidence from interviews with parents, that their children transfer their learning about risk taking, beyond the Forest School environment. Sometimes this was later that same day, recounting what they had done in the wood and other times on family outings: 
My children certainly got a lot out of it, loved it and memories that, you know they still talk about now. They still talk about Forest School and they still go into the woods and you know, (name)'s still excited about finding Fungi, and you know a pretty lasting experience' (Parent 12)

Another parent related how her child had brought a packet of matches to her, having accidentally left them out. She attributed this knowledge to Forest School:

I think it makes children respect fire and I know I've had opportunity where I've left the matches out, we have a fire in our own house and we've by accident left the matches out and my son came to me and said we're not allowed to use these and gave them to me so he knew the rules and he learnt that through Forest School because I haven't taught him that at home' (Parent 22)

Other parental comments also suggested that children transferred their Forest School learning to other environments:

I feel that Forest School has certainly helped my daughter with her physical confidence and development ... the risk assessment skills she has learnt in the forest have been transferred to her play in the garden (Parent 2)

My 3 year old, she is a more safety-conscious person today (Parent 1)

Several parents stated that Forest School gave children opportunities to take risks that they would not necessarily have elsewhere. One parent, for instance, stressed how the Forest School experience contrasted with her own, 'risk averse' tendency:

I know I can be a bit risk averse and I know that I used to get really worried about (name) when he was trying to climb trees in the garden, but I'm more comfortable with him climbing trees now as seems quite competent climbing trees now!

Interviewer: Due to his Forest School experience?

I think it might be. He's grown in confidence in the last 12 months and I think that was Forest School and pre-school and being encouraged, I think, to try different things. (Parent 14)

Parents also mentioned the theme in the literature that children do not play outside as much during free time at home as they did in previous generations. One parent specifically linked this with the increase of digital technology:

kids can't really get outside and play much without supervision at home (Parent 18) 
when we were kids we were always outside weren't we, there were no computer games or anything (Parent 20)

Some of the responses from parents of children with special needs reflected their children's needs, for example when asking about whether children should be in sight of an adult 'yes only because my son isn't aware of danger' (Parent 3) and 'as long as it's contained. I am fairly comfortable for my mainstream child, for my SN [special needs] child I expect an adult' (Parent $10)$.

\section{Children's capabilities}

From an early age, it seems that children understand the risks associated with being out of doors and articulate these. The following statements are in response to the question, 'should you be able to climb trees if you feel safe to do so?'

Not when it's slippery (child 36)

It's ok if there is a grown-up looking (child 2)

Only if a teacher can see you ... you're not allowed to climb taller than the teacher (Child 11)

Some parent responses suggested that they do not really believe that children can self-manage, that they were not confident in what their children are capable of, or that their child is 'only three' (Parent 22) and therefore unable to understand and manage these risks for themselves. However, these fears may be misplaced. For example, during one Forest School session, the leaders found a lot of litter that had been thrown into the Forest area. The Leaders talked to the children about the litter, they put on gloves, gathered it and put it in bin bags. One of the parents later reported that her son had taken on the responsibility, after school, when they were out and about of pointing out where the litter was, and disposing of it, responsibly, in case animals ate it. Anecdotes such as this suggest that at least some children remember what they were told in Forest School sessions, about exercising due caution in taking risks.

\section{Discussion}

The data confirm that parents and practitioners have anxieties around young children understanding the risk associated with the outdoor environment: they worry about what might happen to the children in their care. In response, they can become quite strongly 'risk-averse' or 'permissive' (Waters \& Begley 2007). There are also signs of an attitude to risk which we have termed 'measured'; this accepts the presence of risk within limits. We found this attitude most clearly revealed in the children's data, possibly because, in terms of risk at Forest School, there 
is evidence that children learn not only specific safety rules, but also the reasons for the rules, and hence, a set of general principles of dealing with risk. In terms of the adults, the practitioners' responses tended to be clustered around either 'risk-averse' or 'permissive' constructs, whereas parents' responses tended to contain elements of both, suggesting a somewhat schizophrenic stance: they wanted to keep their children very safe but also to help them develop strong and confident attitudes to risk. This finding might be explained by the fact that, as Borawski et al. (2003) point out,

As children mature and gain independence, parents adjust their supervisory practices to allow for more freedom and independent decision-making (p. 60).

Unlike practitioners, who work in a clearly-defined setting with particular age-groups, and are expected to establish and maintain a relatively unvarying set of rules and procedures, parental monitoring must necessarily change constantly as their children mature. Parental rules and procedures cannot be static, which might explain the anxiety and ambivalence seen in the data are their rules and procedures keeping pace with their children's development or are they perhaps changing too quickly or too slowly?

In this context, parents appreciated Forest School because it provides safe boundaries within which risk can be encouraged; they also appreciate that children are encouraged to assess levels of risk, themselves. Thus, Forest School is seen as one possible answer to the problem of risk. Some of the data suggest that lessons learnt at Forest School, are applied in other contexts (e.g. lessons about the use of matches are taken home). Additionally, all groups, practitioners, parents and children, reported having memorable and positive experiences of Forest School. Transferability of skills, confidence and attitudes to learning from Forest School to other environments was something that greatly interested the research team. As reported above, several parents provided examples of children talking about what they had learned through Forest School and putting this into practice in other environments. However, there was also a recognition that parents do not necessarily take children into outdoor environments:

some parents don't get the chance to spend that time with their kids to show them bugs and trees and things (Parent 18)

it's a good place to learn but they also need their parents to be backing them, it shouldn't just be something they do at nursery (Practitioner 15)

I think it's great as they don't have that opportunity at home, any more (Parent 22) If these perceptions are correct, then children might lack opportunities to transfer their learning to other environments; such lack of opportunity might also apply to their learning about risk. It 
is also possible that, because parents view Forest School as a safe means of children accessing the outdoors, they might therefore limit children's outdoor experience to this 'controlled' access to the outdoors. There is evidence in the data that parents feel less confident about implementing risky outdoor play themselves, with time cited as a factor alongside the concern about child abduction being voiced as another. Although Forest School aims to provide rich and challenging outdoor play experiences for children, in isolation, these will not be enough. Finally, the research team noted an inconsistency between the few specific safety rules in Forest School and those in other settings, including schools. Often it seems that, as soon as children leave Forest School, they are immediately surrounded by rules, not always with a clear reason for them. This inconsistency might militate against the transferability of the Forest School learning around developing the ability to consider risk and act responsibly.

\section{Conclusions}

The research had limitations. First, although we had intended to measure the children's perceptions of risk quantitatively, via interviews with Research Practitioners who were familiar to them, the interview data cast doubt on whether the children really understood the concept of 'strongly agree ... strongly disagree' and we reluctantly abandoned this aspect of the research. Furthermore, the children's interviews responses may have reflected what they thought would please the interviewer. The environment of the interviews - indoors or out of doors - certainly had some effect on the children's responses; one child was interviewed out of doors, and showed much greater responsiveness than in similar situations, indoors. Regarding the quantitative findings from the parent and practitioner data, as statistical significance is dependent on sample size, it is likely that the small to moderate effect sizes found in the nonsignificant results would have reached significance with a larger sample size. Additionally, the questionnaire may not have been sensitive enough to effectively capture differences pertaining to involvement in Forest School; future research may benefit from using a standardised questionnaire that has gone through the process of psychometric validation. Second, there were challenges of sampling. Because all the parents and practitioners who were interviewed were women, there was a considerable gender imbalance (although some of the questionnaires were completed by men). The data collected from children was mostly from the earliest age group, and more data from children in the ages of 5-7 would have provided a more rounded dataset. Also, the popularity of Forest School within this (predominantly rural) county made it difficult to find practitioners and parents with no experience of Forest School, and we had to go beyond the County to obtain a sufficiently large comparative group. Finally, both the survey and the interviews focused on risks in outdoor environments, thus missing the opportunity to compare perceptions of these risks with perceptions of risk more generally. Therefore, further research 
would be necessary to establish children's perceptions of risk, to study the perspectives of those living in urban or suburban areas, and to compare perceptions of 'outdoor' risk with more general perceptions of risk.

Despite these limitations, the study has generated quantitative evidence that engagement with Forest School influences the perceptions of risk held by practitioners. It has also produced qualitative evidence that Forest School can influence the perceptions of risk held by children, and that parents have noticed this influence. These findings are significant because, in today's 'risk society' (Beck 1992; Giddens 1999) people can take either extremely risk-averse, or extremely permissive and fatalistic attitudes to risk.

It is not clear whether the transfer of learning, identified in the study, occurs for all, or even most, children; neither is it clear how long the transfer effect lasts. Indeed, there are at least three factors that militate against transfer: a) some parents may not give their children opportunities for transfer; b) some may see Forest School as providing all that is necessary in terms of outdoor education; and c) the risk-averse and rule-bound indoor environment of schools and settings may cancel out the measured approach to risk in Forest School.

If this is so, Forest School practitioners may need to make conscious efforts to work with families to continue their work into other parts of children's lives, perhaps by involving more parents and family members, including more men. Forest School should be presented as an introduction to outdoor learning, not its totality. It might also be helpful for leaders in schools and settings to consider the principles behind their institutional rules, including those to do with safety, and to work towards an approach that is more consistent with that in Forest School - teaching children to assess risks informally and take responsibility for their own actions, within an environment where risks are not too great.

Additionally, Forest School is not accessible to all children - although it is difficult to obtain reliable numbers, it is likely to be accessed by fewer than half the children in England. Any particular child's engagement with Forest School is largely a matter of chance. Of course there are other organisations who provide outdoor learning experiences but, because Forest School is integrated into schools, it is, in principle, open to everyone, not only those whose parents pay for after-school activities. This means that the benefits of Forest School - including but not limited to influencing attitudes to risk - are not available to all.

More research needs to be done in other settings, with children of older age groups and fathers, as well as mothers. It would be helpful to investigate cases of parental involvement in Forest School, to see whether their perceptions change over time. Such research might help discover 
whether, in their own lives, children can be taught to take healthy attitudes to risk, not only for their own sake, but also for the sake of their own children.

[7247 words]

\section{References}

Borawski, E. A., Ievers-Landis, C. E., Lovegreen, L. D., \& Trapl, E. S. (2003). Parental monitoring, negotiated unsupervised time, and parental trust: The role of perceived parenting practices in adolescent health risk behaviors. Journal of Adolescent Health, 33(2), 60-70.

Beck, U. 1992. Risk society: Towards a new modernity. London: Sage.

BBC (British Broadcasting Company) 2014. Into the Unknown. Online: http://www.bbc.co.uk/programmes/b046prs6

Cohen, L., Manion, L., Morrison, K. (2011) Research Methods in Education Routledge.

Cunningham, H. 2012. The invention of childhood. London: Random House.

Dey, I. 1993. Qualitative Data Analysis Routledge.

Forest School Association 2012. What is Forest School? Online: http://www.forestschoolassociation.org/what-is-forest-school/ accessed 19/05/2014

Giddens, A. 1999. Risk and responsibility. The modern law review, 62(1), 1-10.

Gill, T. 2007. No fear: Growing up in a risk averse society. London: Calouste Gulbenkian Foundation.

Gill, T. 2010. Nothing ventured: Balancing risks and benefits in the outdoors. English Outdoor Learning Council.

Gill. T. 2013. Keynote Address. Annual Conference of the Forest School Association, 12.03.2013

House of Commons (2010). Transforming Education Outside the Classroom. Online: www.publications.parliament.uk/pa/cm200910/cmselect/cmchilsch/418/41807.htm\#a8 [Accessed 22.12.2014].

Jones, T. 2013. How can Forest School sessions improve parental engagement and support children's learning and development within the Early Years Foundation Stage? How will these sessions provide rich and challenging opportunities and effect confidence, self-esteem and relationships amongst all involved? Unpublished MA dissertation: Edge Hill University Knight. S. 2009. Forest Schools and Outdoor Learning in the Early Years. London: Sage. 
Knight. S. 2011. Risk and Adventure in Early Years Outdoor Play: Learning from Forest Schools. London: Sage.

Little, H., Wyver, S. \& Gibson, F. 2011. The influence of play context and adult attitudes on young children's physical risk-taking during outdoor play, European Early Childhood Education Research Journal, 19:1, 113-131.

Louv. R. 2005. Last Child in the Woods: Saving Our Children from Nature Deficit Disorder. London: Atlantic Books.

Maynard, T. 2007. Encounters with Forest School and Foucault: a risky business?, Education 313: International Journal of Primary, Elementary and Early Years Education, 35:4, 379-391

Moss, S. 2012. Natural Childhood. London: National Trust. Online: www.nationaltrust.org.uk/document-1355766991839/ (accessed 22 November 2014)

National Trust. 2014. Reconnecting Children with Nature: Findings of the Natural Childhood Inquiry. Online: www.nationaltrust.org.uk/document-1355773744553/ (accessed 22 November 2014)

O'Brien, L. 2009. Learning outdoors: the Forest School approach. Education 3-13, 37(1), 45-60.

Palmer, S. 2009. 21st Century Boys. London: Orion.

Palmer. S. 2011. Keynote Address, The Institute of Outdoor Learning Forest School Special Interest Group Conference, Liddington Hall, Swindon, 08.10.2011

Taber, K. S. 2007. Classroom-based Research and Evidence-based Practice: A Guide for Teachers SAGE Publications Ltd.

Taylor Powell, E. 1996. Analysing Quantitative Data Maddison, WI: University of Wisconsin.

Waite, S. (2009, April). Outdoor learning for children aged 2-11: Perceived barriers, potential solutions. Conference proceedings of Fourth International Outdoor Education Research Conference, La Trobe University, Beechworth, Australia.

Waite, S. 2010. Losing our way? The downward path for outdoor learning for children aged 211 years, Journal of Adventure Education and Outdoor Learning, 10:2, 111-126.

Waters, J., \& Begley, S. 2007. Supporting the development of risk-taking behaviours in the early years: an exploratory study. Education 3-13, 35(4), 365-377. 
Table 1. Questionnaire responses of practitioners

\begin{tabular}{|c|c|c|c|c|c|c|c|}
\hline $\begin{array}{l}\text { Q. } \\
\text { item }\end{array}$ & $\begin{array}{l}\text { Involvement } \\
\text { with FS }\end{array}$ & Mean & SD & $t$ & $\mathrm{df}$ & $p$ & $\begin{array}{l}\text { Cohen's } \\
d\end{array}$ \\
\hline \multirow[t]{2}{*}{1} & None $(\mathrm{N}=66)$ & 2.24 & 1.35 & \multirow[t]{2}{*}{-3.43} & \multirow[t]{2}{*}{255} & \multirow[t]{2}{*}{$<.003$} & \multirow[t]{2}{*}{.49} \\
\hline & Some (N = 191) & 2.90 & 1.34 & & & & \\
\hline \multirow[t]{2}{*}{2} & None $(\mathrm{N}=66)$ & 3.27 & .95 & \multirow[t]{2}{*}{-2.06} & \multirow[t]{2}{*}{255} & \multirow[t]{2}{*}{.04} & \multirow[t]{2}{*}{.30} \\
\hline & Some $(N=191)$ & 3.57 & 1.03 & & & & \\
\hline \multirow[t]{2}{*}{3} & None $(\mathrm{N}=66)$ & 3.67 & .98 & \multirow[t]{2}{*}{-2.76} & \multirow[t]{2}{*}{255} & \multirow[t]{2}{*}{.003} & \multirow[t]{2}{*}{.39} \\
\hline & Some $(\mathrm{N}=191)$ & 4.04 & .92 & & & & \\
\hline \multirow[t]{2}{*}{4} & None $(\mathrm{N}=66)$ & 3.71 & 1.19 & \multirow[t]{2}{*}{-2.41} & \multirow[t]{2}{*}{255} & \multirow[t]{2}{*}{.02} & \multirow[t]{2}{*}{.34} \\
\hline & Some $(\mathrm{N}=191)$ & 4.09 & 1.06 & & & & \\
\hline \multirow[t]{2}{*}{5} & None $(\mathrm{N}=66)$ & 2.33 & 1.06 & \multirow[t]{2}{*}{-2.09} & \multirow[t]{2}{*}{255} & \multirow[t]{2}{*}{.04} & \multirow[t]{2}{*}{.31} \\
\hline & Some $(\mathrm{N}=191)$ & 2.66 & 1.09 & & & & \\
\hline \multirow[t]{2}{*}{6} & None $(\mathrm{N}=66)$ & 2.42 & 1.15 & \multirow[t]{2}{*}{-1.74} & \multirow[t]{2}{*}{255} & \multirow[t]{2}{*}{.08} & \multirow[t]{2}{*}{.25} \\
\hline & Some $(\mathrm{N}=191)$ & 2.71 & 1.14 & & & & \\
\hline 7 & None $(\mathrm{N}=66)$ & 3.03 & 1.01 & -.77 & 255 & .44 & .11 \\
\hline & Some $(\mathrm{N}=191)$ & 3.14 & .99 & & & & \\
\hline 8 & None $(\mathrm{N}=66)$ & 4.26 & .66 & -1.94 & 255 & .05 & .27 \\
\hline & Some $(\mathrm{N}=191)$ & 4.43 & .60 & & & & \\
\hline 9 & None $(\mathrm{N}=66)$ & 3.53 & .96 & -3.10 & 106.46 & $<.003$ & .45 \\
\hline & Some $(\mathrm{N}=191)$ & 3.95 & .90 & & & & \\
\hline 10 & None $(\mathrm{N}=66)$ & 3.44 & 1.10 & -2.52 & 255 & .01 & .36 \\
\hline & Some $(\mathrm{N}=191)$ & 3.83 & 1.06 & & & & \\
\hline 11 & None $(\mathrm{N}=66)$ & 3.32 & 1.08 & -3.80 & 107.44 & $<.003$ & .55 \\
\hline & Some $(\mathrm{N}=191)$ & 3.90 & 1.02 & & & & \\
\hline 12 & None $(\mathrm{N}=66)$ & 3.20 & 1.14 & -2.55 & 255 & .01 & .36 \\
\hline & Some $(\mathrm{N}=191)$ & 3.60 & 1.08 & & & & \\
\hline 13 & None $(\mathrm{N}=66)$ & 3.47 & 1.01 & -2.86 & 95.94 & $<.003$ & .42 \\
\hline & Some $(\mathrm{N}=191)$ & 3.86 & .82 & & & & \\
\hline 14 & None $(\mathrm{N}=66)$ & 3.67 & .75 & -1.18 & 255 & .24 & .16 \\
\hline & Some $(\mathrm{N}=191)$ & 3.79 & .77 & & & & \\
\hline 15 & None $(\mathrm{N}=66)$ & 4.36 & .87 & -1.33 & 255 & .19 & .19 \\
\hline & Some $(N=191)$ & 4.52 & .78 & & & & \\
\hline
\end{tabular}

Notes: $\mathrm{p}$ values were adjusted for one-tailed tests; $\mathrm{p}$ must be below .003 to be significant as a Bonferroni correction was applied; Cohen's $d=0.2$ is a small effect; $d=0.5$ is a medium effect; $d$ $=0.8$ is a large effect. The results indicate that involvement with Forest School impacts on practitioners' perceptions of risk, although not in all areas. 